\title{
We Need To Look At the Comorbidities of Obesity during Childhood and Adolescence
}

\author{
Carlos Alberto Nogueira-de-Almeida* \\ Medical Department, Federal University of São Carlos (UFSCAR), Brazil
}

Received: December 06, 2017; Published: December 13, 2017

*Corresponding author: Carlos Alberto Nogueira-de-Almeida, UFSCAR, Rua Eugênio Ferrante, 170 14027-150 Ribeirão Preto, SP, Brazil, Tel: 551699221 7498; Email: dr.nogueira@me.com

\section{Opinion}

Nowadays, almost $50 \%$ of boys and girls with ages between 5 and 9 years old are overweight or obese. And these children frequently have one or more comorbidities. Unfortunately, there is a wrong belief that the great problem of obese children is the risk of this child to be an obese adult. In fact, there are a lot of comorbidities that already appears during infancy and, if treated, probably will not progress to adulthood. We have been studying some of these comorbidities from the last 5 years. We studied dyslipidemia and insulin resistance and we found that $69.4 \%$ of the children had high cholesterol, 45.2\% high LDL, 54.8\% low HDL and $53.2 \%$ high triglycerides [1]. It is consensual that we have a vicious circle including obesity and insulin resistance [2] and we evaluated 383 children with ages between 7 and 18 years using fasting insulinemia and Homa as indicators of insulin resistance. The prevalence was very high, independently of the method: $33.1 \%$ using fasting insulin $>15$ and $37.8 \%$ using HOMA> 3.5 [1]. We also looked at blood pressure and we showed high blood pressure values among obese children, when compared to eutrophic children [3-5].

Regarding the heart, we investigated if obese children, with ages between 6 and 9 years, has detectable modifications of the heart anatomy, especially regarding to the left ventricle, and we found that, among 5 index evaluated, two of them (the LV mass and the LV3 index) showed differences, with greater thickness of the ventricle among obese children [4]. The intima-media complex of common carotid artery can be accessed using ultrasonography. This is a very safe and accurate method to evaluate the onset appearance of atherosclerosis. We evaluated 59 children of both genders, between 7 and 10 years old [5]. The average thickness of the intima-media complex in the group overweight / obese was $0.49 \mathrm{~mm}$; in the non-obese group, the measurement was $0.41 \mathrm{~mm}$. There was a significant difference between groups ( $p<0.01)$.And, also, we showed a correlation between the increase of the z-score of BMI and the increase of the intima-media complex [6]. The waist circumference is nowadays considered very important for children health [7]. We evaluated the abdominal adiposity distribution [8].
Results from 59 children of both genders, between 7 and 10 years old showed high correlation of fat deposits between each other and the two compartments of abdominal fat deposition increased together. And, even more important, both subcutaneous fat and visceral fat showed almost the same correlation with abdominal circumference.

This means that, at this age, when we measure the abdomen, we are measuring both visceral and subcutaneous fat and this two measurements increase together with the increase of the abdominal circumference [8]. At this same study, we evaluated the liver and a hiperechoic image is an indicator of the presence of Non Alcoholic fat Liver Disease (NAFLD). Children with normal liver tend to have less subcutaneous fat then children with more echoic liver. And, similarly, children with normal liver tend to have less visceral fat then children with more echoic liver [8]. In conclusion, even among school children, we could find a lot of obesity comorbidities, as: dyslipidemia, insulin resistance, high blood pressure, left ventricle hypertrophy, carotid intima hypertrophy, visceral fat accumulation and NAFLD. And we need to treat these children early, to prevent the evolution to adult diseases and to give them a better quality of life.

\section{References}

1. Nogueira-de-Almeida CA, Pires LA, dos Santos RG (2016) Comparação de indicadores de perfis glicêmico e lipídico entre crianças e adolescentes obesos egressos de serviço público ou privado da cidade de Ribeirão Preto (SP). Medicina (Ribeirao Preto Online) 49(6): 504-510.

2. De Almeida CAN, Pinho AP, Ricco RG, Pepato MT, Brunetti IL (2008) Determination of glycemia and insulinemia and the homeostasis model assessment (HOMA) in schoolchildren and adolescents with normal body mass index. Jornal de pediatria 84(2): 136-140.

3. Nogueira-de-Almeida CA, Caixe SH, Benedeti ACGS, Garcia J (2016) Echocardiography Evaluation as a Marker of Cardiovascular Risk on Obese Children and Adolescents. The FASEB Journal 30(1): 126.1.

4. Caixe SH, Garcia Saab Benedeti AC, Garcia J, Martins WdP, Mauad Filho F, et al. (2014) Evaluation of Echocardiography as a Marker of Cardiovascular Risk in Obese Children and Adolescents 3(3): 72-78. 
5. Costa KCM, Lima JC, Almeida CANd, Ciampo LAD, Souza CSBd (2012) Variation of the brachial artery diameter in obese children: present and future. Revista Paulista de Pediatria 30(3): 431-437.

6. Nogueira-de-Almeida CA, Garcia J, Caixe SH, Benedeti ACGS (2016) Ultrasonographic Assessment of the Common Carotid Intima-Media Complex in Normal Weight Children and in Overweight/Obese Children. The FASEB Journal 30(1): 1163-1165.
7. De Almeida CA, Pinho AP, Ricco RG, Elias CP (2007) Abdominal circumference as an indicator of clinical and laboratory parameters associated with obesity in children and adolescents: comparison between two reference tables. J Pediatr (Rio J) 83(2): 181-185.

8. Nogueira-de-Almeida CA, Benedeti ACGS, Garcia J, Caixe SH (2016) Correlation Between Ultrasonographic Measures of the Abdominal Adiposity and Indicators of Obesity in Normal and Overweight/Obesity Children. The FASEB Journal 30(1): 1165.4.

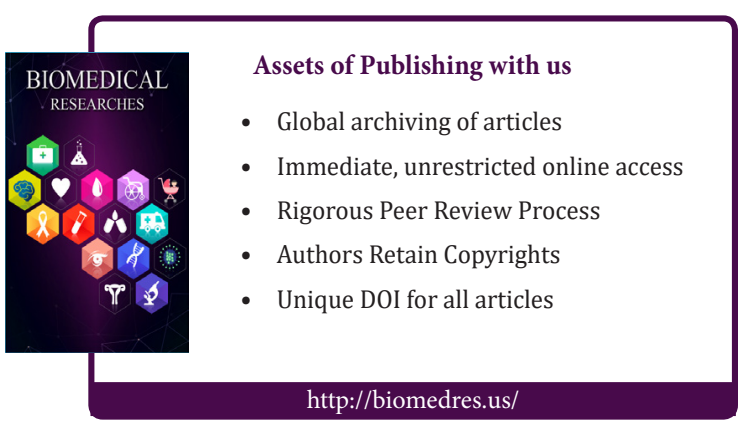

